\title{
Spinal epidural abscess - a rare complication of inflammatory bowel disease
}

\author{
Carl J Brown MD MSc FRCSC ${ }^{1,4}$, Hussein Jaffer ${ }^{1,4}$, Nasir Jaffer MD FRCPC 2,4 , \\ Claude Burul MD FRCSC ${ }^{5}$, Robin S McLeod MD FACS FRCSC ${ }^{1,3,4}$
}

CJ Brown, H Jaffer, N Jaffer, C Burul, RS McLeod. Spinal epidural abscess - a rare complication of inflammatory bowel disease. Can J Gastroenterol 2008;22(2):177-180.

Spinal epidural abscess is an uncommon but highly morbid illness. While it usually afflicts older, immunocompromised patients, this condition has been reported as a result of intestinal perforation in the setting of inflammatory bowel disease. Two cases of spinal epidural abscess in patients with inflammatory bowel disease are reported: one in a patient with Crohn's disease and one in a patient with ulcerative colitis after restorative proctocolectomy.

\section{Abcès spinal épidural : Complication rare de la maladie inflammatoire de l'intestin}

\begin{abstract}
L'abcès spinal épidural est une maladie rare mais extrêmement morbide. Bien qu'il affecte généralement des patients plus âgés et immunodéprimés, ce type d'abcès a été signalé après une perforation intestinale dans le contexte de la maladie inflammatoire de l'intestin. Deux cas d'abcès spinal épidural chez des patients atteints de maladie inflammatoire de l'intestin sont décrits ici. L'un chez un patient atteint de la maladie de Crohn et l'autre, chez un patient atteint de colite ulcéreuse ayant subi une proctocolectomie correctrice.
\end{abstract}

Key Words: Abscess; Crohn's disease; Ileal pouch; Inflammatory bowel disease; Spinal abscess; Ulcerative colitis

Crohn's disease is complicated by perforation, abscesses $\checkmark$ and fistulas in $30 \%$ to $50 \%$ of patients $(1,2)$. Approximately one-half of the resultant fistulas are perianal, with entero-enteric and enterocutaneous fistulas comprising the majority of the remainder (2). Rarely, Crohn's diseaseassociated fistulas develop between the intestine and other organs, such as the genitourinary tract $(3,4)$, uterus $(5)$ and even the bronchial tree (6-8). Fistulous communication to the epidural space has also been reported (9-18). In ulcerative colitis, the development of a fistula is rare. However, after restorative proctocolectomy, pouch-related fistulas are reported in approximately $5 \%$ of patients $(19,20)$.

We report two cases of fistulas that extended from the intestine to the epidural space, resulting in epidural abscesses, sepsis and neurological compromise.

\section{Case 1}

\section{CASE PRESENTATIONS}

A 28-year-old woman presented to the emergency department at a peripheral hospital with a three-week history of worsening lower back pain complicated by sudden onset of right leg weakness and paresthesia. She had an eight-year history of Crohn's disease that was confined to the terminal ileum. She had been treated intermittently with oral prednisone for disease flares, but had not required therapy for the previous six months.

On admission, she was afebrile $\left(37.1^{\circ} \mathrm{C}\right)$, but tachycardic (112 beats/min) and her blood pressure was 110/80 mmHg. A computed tomography (CT) scan of the abdomen and pelvis revealed a presacral mass that was interpreted as a possible malignancy. She was admitted to the hospital, and a CT-guided biopsy of the lesion revealed purulent material consistent with an abscess. Intravenous vancomycin, ciprofloxacin and metronidazole therapy was initiated, and she was transferred to a tertiary care unit for neurosurgical assessment.

Her vital signs were unchanged after transfer. Cardiac, pulmonary and abdominal examinations were unremarkable; however, there was a palpable 'fullness' in the right lower quadrant on deep palpation. Neurological assessment revealed some perineal and right buttock anesthesia, slightly decreased anal tone, and weakened left-leg dorsi flexion, plantar flexion and knee extension. She had a slightly unsteady gait, but the remainder of the neurological examination was normal. Laboratory values showed a white blood cell count of $22.9 \times 10^{9} / \mathrm{L}$, a hemoglobin level of $80 \mathrm{~g} / \mathrm{L}$ and an erythrocyte sedimentation rate of $120 \mathrm{~mm} / \mathrm{h}$. Magnetic resonance imaging (MRI) of the lumbar spine showed an epidural abscess from L5 to S3 (Figure 1). A CT scan of the pelvis revealed multiple bilateral paraspinal abscesses and a 'ringenhancing' inflammatory mass in the epidural space (Figure 2A), as well as a thickened distal ileum tethered toward the inflammatory presacral abscess (Figure 2B). After $12 \mathrm{~h}$ of intravenous fluid resuscitation and antibiotic therapy, the patient's tachycardia improved and she had subjective improvement in both her pain and leg weakness. The neurosurgery team decided to continue medical management. Total parenteral nutrition (TPN) was initiated. Two days after admission, cultures of the previously aspirated fluid revealed Streptococcus milleri, and the infectious diseases consultant changed her antibiotic therapy to intravenous ceftriaxone and metronidazole.

\footnotetext{
${ }^{1}$ Department of Surgery; ${ }^{2}$ Department of Radiology; ${ }^{3}$ Department of Health Policy, Management and Evaluation, Samuel Lunenfeld Research Institute; Mount Sinai Hospital and the University of Toronto; ${ }^{5}$ Department of Surgery, Toronto Western Hospital, Toronto, Ontario Correspondence: Dr Robin S McLeod, Room 449, Mount Sinai Hospital, 600 University Avenue, Toronto, Ontario M5G 1 X5.

Telephone 416-586-8534, fax 416-586-8644, e-mail rmcleod@mtsinai.on.ca

Received for publication February 7, 2007. Accepted April 20, 2007
} 


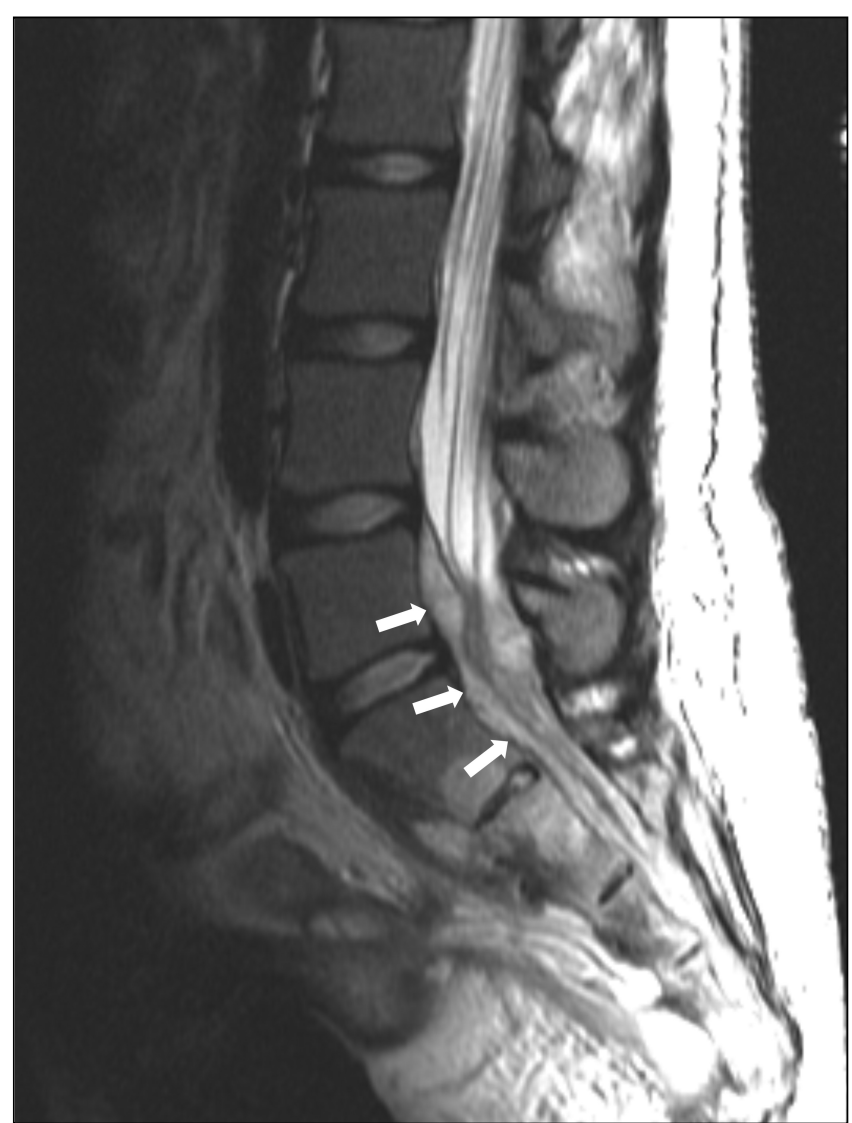

Figure 1) A sagittal magnetic resonance imaging scan of the lumbar spine, showing epidural abscesses from L5 to S3 (arrows). Soft tissue mass is seen in the presacral space corresponding to the abscesses

Over the following two weeks, the patient's back pain and neurological symptoms slowly improved with bowel rest and antibiotics. Colonoscopy to the splenic flexure revealed no abnormalities. After two more weeks of medical management, the patient's symptoms had completely resolved and she was discharged on TPN and antibiotics. Three weeks later, the patient returned for elective ileocolic resection. The terminal ileum was adherent to the retroperitoneum in the pelvis at the top of the sacrum. On pathological evaluation, there was evidence of active Crohn's disease and local perforation. There was no residual pus, so an ileocolic resection and primary anastomosis was performed. Her postoperative recovery was uneventful and she was discharged after nine days. Her TPN and intravenous antibiotics were discontinued, but oral amoxicillin and clavulanic acid therapy was continued for a total of 12 weeks. At a one-year follow-up examination, there was no evidence of recurrent Crohn's disease and she had had complete neurological recovery.

\section{Case 2}

A 29-year-old woman presented to a peripheral hospital with neck stiffness, headache and photophobia. She had been diagnosed with ulcerative colitis 18 years previously and underwent a total abdominal colectomy 10 years previously for disease refractory to medical management. Despite some suspicion about the diagnosis due to an interim perianal abscess and a sibling with Crohn's disease, she underwent an ileal pouch procedure with diverting loop ileostomy at Mount Sinai
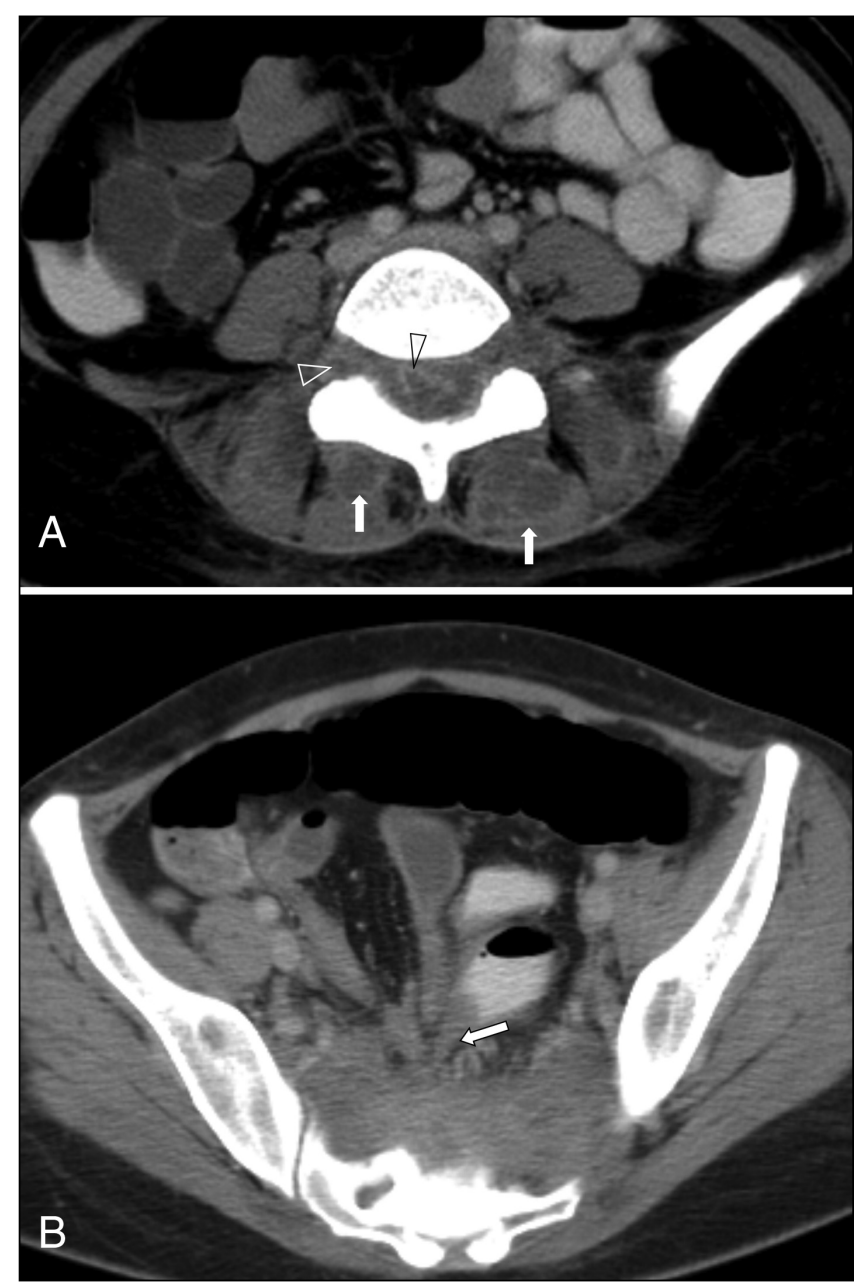

Figure 2) A Axial computed tomography scan at the level of L5 to S1 disc space, showing multiple bilateral paraspinal abscesses (arrow) and 'ring enhancing' inflammatory masses in the epidural, and both right and left sacral foramina (open arrowheads). B Axial computed tomography scan of the lower pelvis, showing a thickened distal ileum tethered toward the inflammatory presacral abscess (arrow)

Hospital (Toronto, Ontario). One week postoperatively, the patient developed a fever and had a CT scan, which revealed a pelvic abscess and a leak from both the pouch and the ileoanal anastomosis. The abscess was successfully treated with antibiotics and percutaneous drainage. The follow-up pouchogram was normal, so the ileostomy was closed.

Following surgery, the patient generally did well, averaging six to eight bowel movements per day. However, on several occasions, she presented with increased stool frequency associated with pelvic pain. Endoscopies on these occasions showed inflammation of the pouch consistent with pouchitis and she was treated with antibiotics.

Seven years after pouch creation, the patient presented with neck stiffness, headache and photophobia. At this presentation, the patient underwent a lumbar puncture, which revealed a neutrophilic pleocytosis. An MRI scan demonstrated an epidural abscess. The neurosurgery team determined that urgent drainage through a laminotomy was warranted. Postoperatively, she received a 30-day course of antibiotics. Six months later, a follow-up MRI scan revealed postoperative 
changes at the S1 lamina consistent with the previous infection. The cause of the epidural abscess was not determined.

Three years later, the patient presented for a follow-up examination at Mount Sinai Hospital, with a complaint of passing gas through her vagina. A pouchogram demonstrated a small fistula tract extending from the top of the pouch to the presacral space, but no pouchvaginal fistula. Given the patient's history of an epidural abscess, pouch excision with possible reconstruction was recommended, but the patient refused because her symptoms were minimal and she did not want to have an ileostomy, either temporarily or permanently. Two months later, the patient developed pain radiating down her right leg. A CT scan again demonstrated the pouch fistula in the presacral space (Figure 3A), with a gas bubble extending into the S1 foramen on the right side (Figure 3B). Sclerotic changes in the sacrum suggested chronic or previously treated osteomyelitis. A second pouchogram demonstrated a pouchvaginal fistula. She was admitted to the hospital and treated with intravenous antibiotics, and within a few days, her leg pain resolved. Subsequently, the patient agreed to have surgery, but wanted to preserve her pouch. She underwent a combined abdominal/perineal pouch reconstruction. At surgery, there was dense fibrosis and granulation tissue posteriorly on the right, from the level of S1 to the levator ani. The pouch was excised, a new pouch was created with a hand-sewn ileo pouch anal anastomosis and a defunctioning ileostomy was performed. She is currently awaiting closure of her ileostomy.

\section{DISCUSSION}

Spinal epidural abscess is an uncommon condition, with an incidence of approximately one case per 10,000 hospital admissions (21). Although this is a relatively uncommon condition, it is highly morbid and has an overall mortality rate of nearly $15 \%$ (22).

Retroperitoneal perforation and subsequent abscess is a well recognized complication of Crohn's disease (23-27). However, the development of the more sinister spinal epidural abscess is rare, with only 10 cases reported in the Englishlanguage medical literature $(9-18,28,29)$. While epidural abscesses are typically seen in patients aged 60 to 70 years (30), the ages of the patients with abscesses related to Crohn's disease ranged from 11 to 41 years. The presenting symptoms in these patients are typical of epidural abscesses: back pain that occasionally radiated down one leg, paresthesia and signs of sepsis (eg, fever and elevated white blood cell count). Surgical decompression and antibiotic therapy are the current standard therapies for spinal epidural abscesses (30,31). Most of the patients with an epidural abscess associated with Crohn's disease underwent immediate surgical drainage of the abscess. However, our patient was successfully treated with antibiotics and bowel rest, with subsequent surgical resection of the terminal ileum after the acute inflammation had settled. This approach was justified in our patient, given her rapid clinical improvement on intravenous antibiotics. All case reports of epidural abscess secondary to Crohn's disease describe resolution of symptoms and successful outcomes after intestinal resection.

Spinal epidural abscess after the ileal pouch anal anastomosis has only been reported once in the literature (32). That patient was a 42-year-old man who underwent restorative proctocolectomy for indeterminate colitis and presented with back pain, fever and lower extremity neurological deficit, years

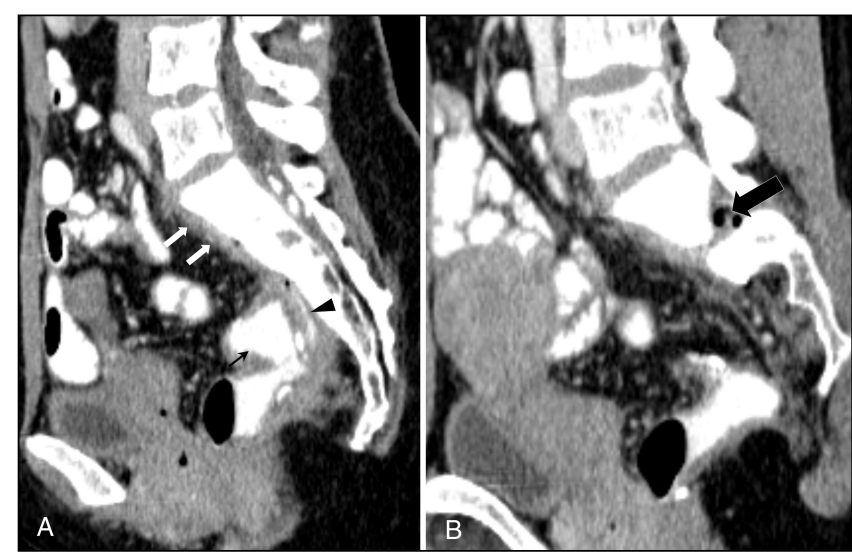

Figure 3) A Sagittal computed tomography scan of the ileal pouch (black arrow), showing a leak from the posterior aspect of the ileoanal pouch (black arrowhead), with a thin layer of presacral abscesses (white arrows). B Sagittal computed tomography scan image to the left of the midline, showing pockets of gas with an ill-defined abscess in the intervertebral foramen in the epidural space (arrow)

later. MRI of the pelvis revealed a presacral abscess, and the patient underwent acute surgical drainage and subsequent pouch excision, as well as end ileostomy formation. Interestingly, the patient had described some sacral discomfort since the pouch construction, suggesting the possibility of an undetected anastomotic leak that eventually evolved into a spinal abscess. In retrospect, the symptoms in our patient that were attributed to pouchitis were likely due to a persistent leak that was palliated by antibiotics. While our patient did have a perianal abscess before pouch creation, all pathological evidence to date is consistent with ulcerative colitis.

\section{CONCLUSIONS}

In patients with Crohn's disease or restorative proctocolectomy who develop back pain with lower extremity neurological deficit and signs of sepsis, intestinal perforation and spinal epidural abscess should be suspected. Antibiotic therapy and radiological investigation should be initiated immediately. Once the diagnosis is confirmed, urgent neurosurgical consultation should be initiated. While most patients will require surgical drainage of the abscess, patients with dramatic clinical improvement with medical management may warrant nonoperative therapy as a bridge to definitive surgical resection of the intestinal source.

Dr Brown was supported by a research grant from the National Colorectal Cancer Campaign and the Ogden-Goldstein research award.

\section{REFERENCES}

1. Bell SJ, Williams AB, Wiesel P, Wilkinson K, Cohen RC, Kamm MA. The clinical course of fistulating Crohn's disease. Aliment Pharmacol Ther 2003; 17:1145-51.

2. Schwartz DA, Loftus EV Jr, Tremaine WJ, et al. The natural history of fistulizing Crohn's disease in Olmsted County, Minnesota. Gastroenterology 2002;122:875-80.

3. Ben-Ami H, Ginesin Y, Behar DM, Fischer D, Edoute Y, Lavy A. Diagnosis and treatment of urinary tract complications in Crohn's disease: An experience over 15 years. Can J Gastroenterol 2002;16:225-9.

4. Yamamoto T, Keighley MR. Enterovesical fistulas complicating Crohn's disease: Clinicopathological features and management. Int J Colorectal Dis 2000;15:211-5. 
5. Wulfeck D, Williams T, Amin A, Huang TY. Crohn's disease with unusual enterouterine fistula in pregnancy. J Ky Med Assoc 1994;92:267-9.

6. Domej W, Kullnig P, Petritsch W, et al. Colobronchial fistula: A rare complication of Crohn's colitis. Am Rev Respir Dis 1990;142:1225-7.

7. Mera A, Sugimoto M, Fukuda K, et al. Crohn's disease associated with colo-bronchial fistula. Intern Med 1996;35:957-60.

8. Singh D, Cole JC, Cali RL, Finical EJ, Proctor DD. Colobronchial fistula: An unusual complication of Crohn's disease. Am J Gastroenterol 1994;89:2250-2.

9. Aitken RJ, Wright JP, Bok A, Elliot MS. Crohn's disease precipitating a spinal extradural abscess and paraplegia. Br J Surg 1986;73:1004-5.

10. Burke V, Mall JC. Epidural gas: An unusual complication of Crohn disease. AJNR Am J Neuroradiol 1984;5:105-6.

11. Heidemann J, Spinelli KS, Otterson MF, Binion DG. Case report: Magnetic resonance imaging in the diagnosis of epidural abscess complicating perirectal fistulizing Crohn's disease. Inflamm Bowel Dis 2003;9:122-4.

12. Hershkowitz S, Link R, Ravden M, Lipow K. Spinal empyema in Crohn's disease. J Clin Gastroenterol 1990;12:67-9.

13. Lamport RD, Cheskin LJ, Moscatello SA, Nikoomanesh P. Sterile epidural and bilateral psoas abscesses in a patient with Crohn's disease. Am J Gastroenterol 1994;89:1086-9. (Comment in 1995;90:1183-4).

14. Maggiore R, Miller F, Stryker S, Buchman AL. Meningitis and epidural abscess associated with fistulizing Crohn's disease. Dig Dis Sci 2004;49:1461-5.

15. Pande KC, Prince HG, Kerslake RW. Vertebral osteomyelitis as a complication of Crohn's disease. Eur Spine J 1998;7:165-7.

16. Piontek M, Hengels KJ, Hefter H, Aulich A, Strohmeyer G. Spinal abscess and bacterial meningitis in Crohn's disease. Dig Dis Sci 1992;37:1131-5.

17. Sacher M, Gopfrich H, Hochberger O. Crohn's disease penetrating into the spinal canal. Acta Paediatr Scand 1989;78:647-9.

18. West D, Russell TR, Brotman M. Rectalepidural fistula complicating Crohn's enterocolitis. Dis Colon Rectum 1983;26:622-4.
19. Paye F, Penna C, Chiche L, Tiret E, Frileux P, Parc R. Pouchrelated fistula following restorative proctocolectomy. Br J Surg 1996;83:1574-7.

20. Rossi HL, Brand MI, Saclarides TJ. Anal complications after restorative proctocolectomy (J-pouch). Am Surg 2002;68:628-30

21. Rigamonti D, Liem L, Sampath P, et al. Spinal epidural abscess: Contemporary trends in etiology, evaluation, and management. Surg Neurol 1999;52:189-96.

22. Reihsaus E, Waldbaur H, Seeling W. Spinal epidural abscess: A meta-analysis of 915 patients. Neurosurg Rev 2000;23:175-204.

23. Agha FP, Woolsey EJ, Amendola MA. Psoas abscess in inflammatory bowel disease. Am J Gastroenterol 1985;80:924-8.

24. Burul CJ, Ritchie JK, Hawley PR, Todd IP. Psoas abscess: A complication of Crohn's disease. Br J Surg 1980;67:355-6.

25. Durning P, Schofield PF. Diagnosis and management of psoas abscess in Crohn's disease. J R Soc Med 1984;77:33-4.

26. Kyle J. Psoas abscess in Crohn's disease. Gastroenterology 1971;61:149-55.

27. Ogihara M, Masaki T, Watanabe T, et al. Psoas abscess complicating Crohn's disease: Report of a case. Surg Today 2000;30:759-63.

28. Hefter H, Piontek M, Aulich A. Bacterial meningitis and dorsal spinal epidural abscess caused by Crohn's disease. Neurology 1991;41:606-8.

29. Wallace JR, Luchi M. Crohn's disease complicated by meningitis and spinal epidural abscess. Clin Infect Dis 1995;20:1428-9.

30. Bluman EM, Palumbo MA, Lucas PR. Spinal epidural abscess in adults. J Am Acad Orthop Surg 2004;12:155-63.

31. Lyu RK, Chen CJ, Tang LM, Chen ST. Spinal epidural abscess successfully treated with percutaneous, computed tomographyguided, needle aspiration and parenteral antibiotic therapy: Case report and review of the literature. Neurosurgery 2002;51:509-12.

32. Murr MM, Metcalf AM. Spinal epidural abscess complicating an ileal J-pouch-anal anastomosis. Report of a case. Dis Colon Rectum 1993;36:293-4. 


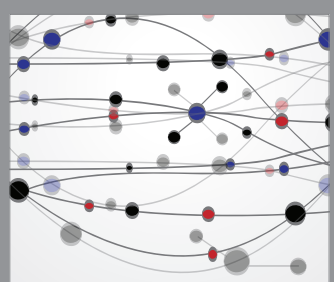

The Scientific World Journal
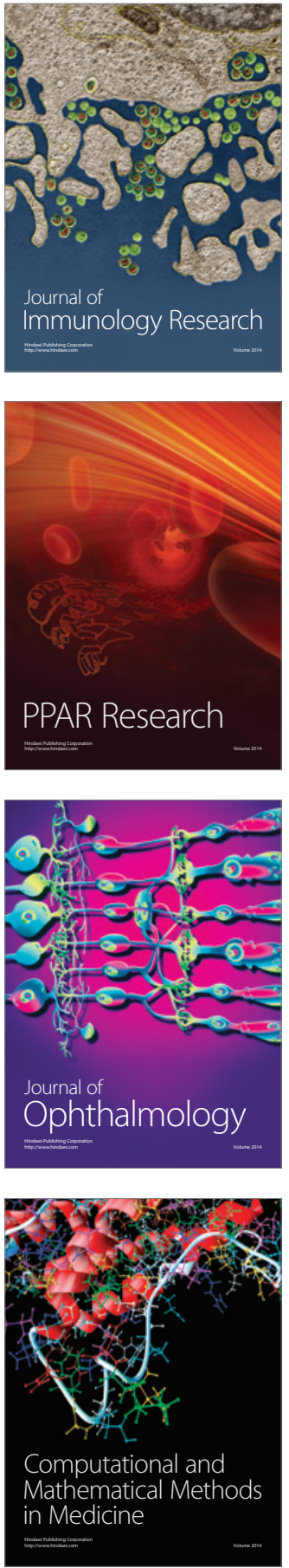

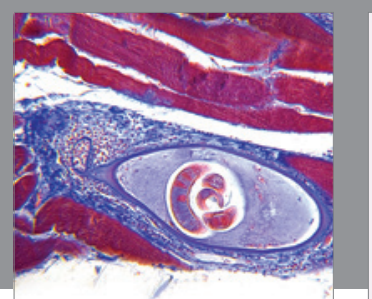

Gastroenterology Research and Practice

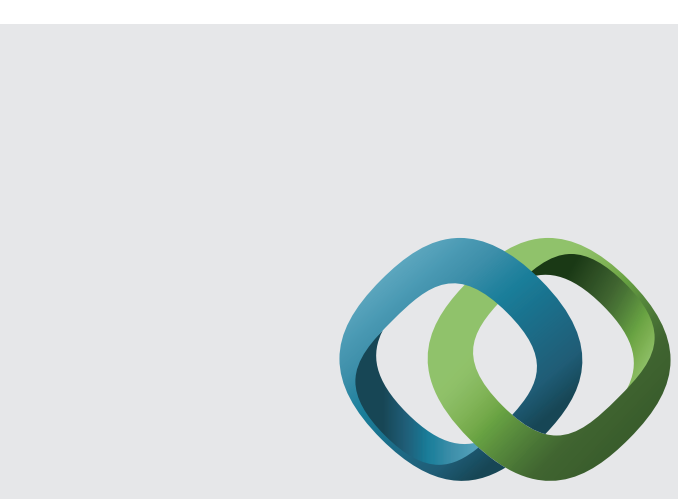

\section{Hindawi}

Submit your manuscripts at

http://www.hindawi.com
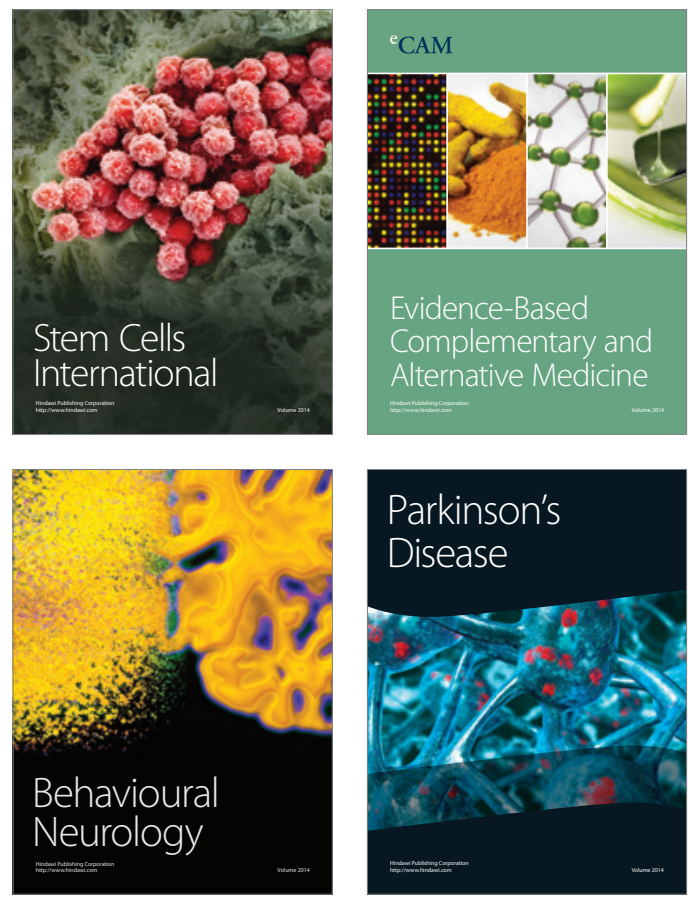
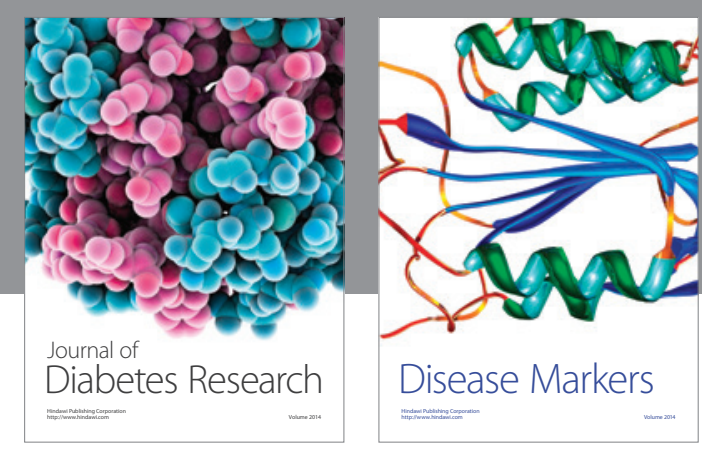

Disease Markers
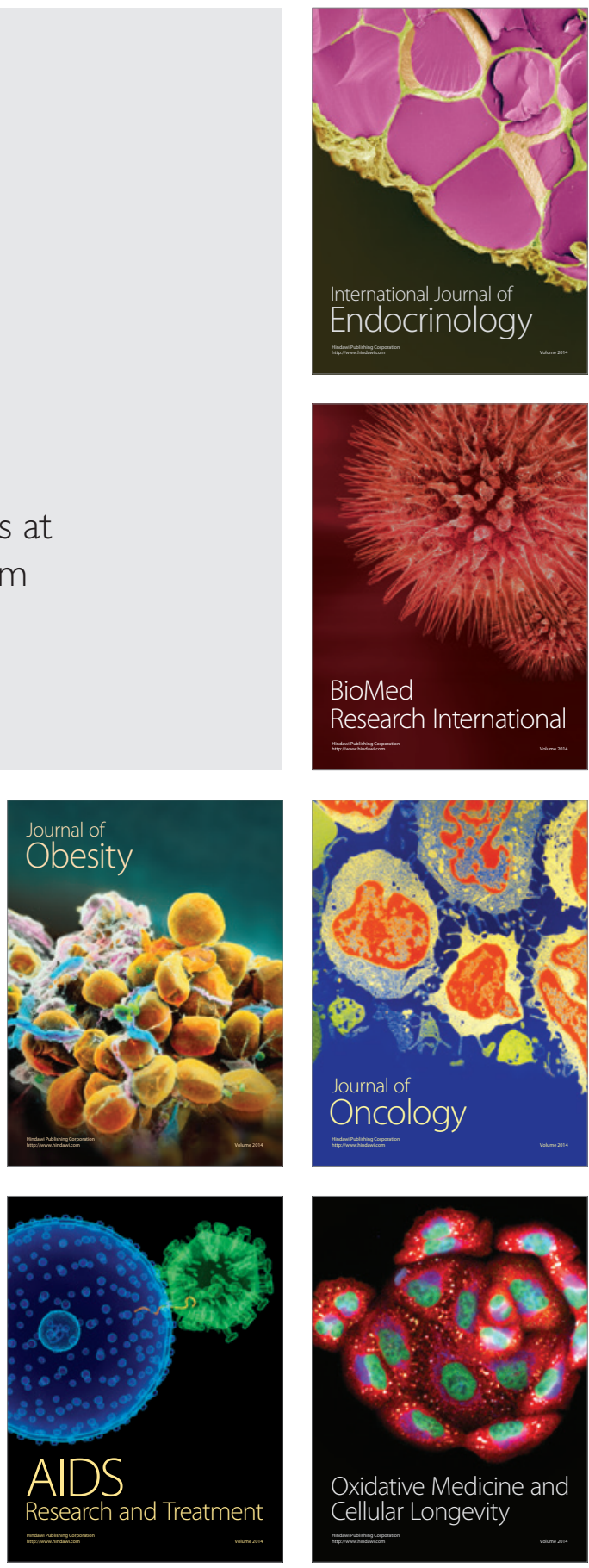